\title{
Educação Física na Educação Infantil: discutindo a formação inicial $e$ o interesse de atuação de acadêmicos de Educação Física/Licenciatura neste nível de ensino
}

\author{
Phisycal Education in Early Childhood Education: discussing the \\ initial formation and the working interest of Physical Education \\ undergraduate studens in this level of education
}

Bruna Girelli Pochmann, ${ }^{1}$ Derli Juliano Neuenfeldt. ${ }^{1}$
${ }^{1}$ Centro Universitário UNIVATES, Lajeado, RS, Brasil.

Recebido em: fevereiro 2015 / Aceito em: março 2015

brunagpochmann@yahoo.com.br

\section{RESUMO}

De acordo com a Lei de Diretrizes e Bases da Educação Nacional, a Educação Física é componente curricular obrigatório para e Educação Básica, que abrange Educação Infantil, Ensino Fundamental e Ensino Médio. Objetivo: analisar e discutir a formação inicial e o interesse de atuação de acadêmicos de Educação Física, na Educação Infantil. Método: pesquisa qualitativa realizada com trinta acadêmicos de um curso de Educação Física - Licenciatura do RS/Brasil, que no semestre 2014B possuíam 80\% da graduação concluído e com três professores que ministram aulas neste mesmo curso. Para a coleta de dados, foi aplicado um questionário contendo onze questões para os alunos e com os professores foi realizada uma entrevista semi-estruturada. A análise dos dados foi realizada, através da interpretação das respostas dos questionários e entrevistas, sendo estabelecidas categorias de análise para que fosse possível desenvolver uma reflexão sobre o estudo. Resultados e considerações finais: pode-se perceber que os alunos estão preparados para atuar com a Educação Infantil, pois disseram ter preparo, apesar de alguns não conhecerem métodos de ensino que podem ser aplicados nas aulas de Educação Física, para Educação Infantil. O possível campo de atuação mais citado pelos alunos foi os Anos Iniciais do Ensino Fundamental, que obteve $30 \%$ de escolha. Pôde-se perceber que se faz necessário reavaliar o currículo do curso para que os alunos possam ter uma melhor compreensão das contribuições da Educação Física, na Educação Infantil.

Palavras-chave: Educação Física; Formação Inicial; Educação Infantil.

\section{ABSTRACT}

According to the guideline of Education Ministry from Brazil, Physical Education is a mandatory component of the curriculum for the Basic Education, which covers Childhood Education, Elementary School and High School. Objective: this paper aimed to analyze and discuss the primary formation and the interest of Physical Education undergraduate students on teach in Childhood Education. Method: a qualitative research was made with thirty academics of a Physical Education course from south Brazil that in the second semester of 2014 had $80 \%$ of the graduation concluded, and with three teachers who give classes in this course. To collect the data a questionnaire with eleven questions was applied with the students, but with the professors was applied a semi-structured interview. Data analysis was made through the questionnaire interpretation and interview answers, establishing some analysis categories in order to improve the reflection about the study. Results and Final considerations: we conclude that the analyzed students are prepared to teach in Childhood Education. This is because they state to be prepared enough to do it, despite some didn't know teaching methods that could be used in this education level. The possible acting field most cited by the students was the Early Years of the Elementary School, which obtained $30 \%$ of choice. It could be noticed that the course curriculum must be revaluated to provide for the students a better understanding on the Physical Education contributions for the Childhood Education.

Keywords: Physical Education; Primary Formation; Childhood Education. 
A pesquisa foi aprovada pelo Comitê de Ética e Pesquisa pelo Parecer Consubstanciado $n^{\circ} 791.309$, de 09/09/2014.

\section{INTRODUÇ̃̃O}

Atualmente, é possível perceber a importância que as escolas de Educação Infantil possuem na sociedade. Os pais trabalham e realizam suas atividades diárias, necessitando, assim, de algum local apropriado para seus filhos que, além de acolher as crianças, tenha em foco o ensino e a aprendizagem. Desta forma, a procura por escolas de Educação Infantil têm sido cada vez maior.

Entendemos que uma das diversas finalidades das instituições de Educação Infantil é prezar pelo bem estar e conforto das crianças. Em muitos casos, as crianças acabam passando mais tempo nas instituições do que, em casa, com a família e isto reforça a necessidade das famílias em saberem o que elas estão aprendendo nas escolas de Educação Infantil.

Inicialmente, é importante considerarmos que, no Brasil, a Educação Infantil percorreu um longo caminho, o qual em certos momentos vinculou-se à saúde em seus pressupostos higienistas; em outros, à caridade e ao amparo à pobreza, e em outros ainda, à educação. As escolas de Educação Infantil não possuem mais a finalidade de somente cuidar da criança, de realizar a higiene de cada uma, de alimentar e de brincar sem ter algum objetivo. Isso tudo ainda faz parte da rotina da Educação Infantil, porém existem outros objetivos a serem alcançados ${ }^{1}$.

Segundo a Lei de Diretrizes e Bases da Educação Nacional (LDBEN) ${ }^{2}$, a Educação Infantil é a primeira etapa da Educação Básica e visa o desenvolvimento integral da criança. Nessa diretriz, a Educação Física consta como componente curricular obrigatório da educação básica integrada à proposta pedagógica da escola.

Assim, percebendo a importância que este nível de ensino representa para a formação das crianças, bem como a necessidade de professores de diversas áreas para atuar na Educação Infantil, este artigo tem como propósito problematizar a formação dos professores de Educação Física, em relação à Educação Infantil e o seu interesse em atuar neste nível de ensino. O tema surgiu a partir de vivências profissionais obtidas, durante dois anos de estágio não-obrigatório com crianças de zero a seis anos de idade, o qual despertou inquietudes em relação à formação do professor de Educação Física, para atuar neste nível de ensino.

Investir na formação dos profissionais que atuam nessa área é um dos caminhos a serem seguidos. Historicamente esses educadores, em sua grande maioria, sobretudo os que atendem à demanda das camadas mais empobrecidas da população, têm sua prática ancorada na paciência, no gostar de criança, em não ter uma formação profissional ou em ter um trabalho próximo às suas casas ${ }^{1}$.

As justificativas para a pesquisa são a busca de conhecimentos que possam propor melhorias na área da Educação Física para a Educação Infantil e contribuir para a melhor formação dos futuros professores.

Assim, o objetivo do presente estudo é analisar e discutir a formação inicial e o interesse de atuação de acadêmicos de Educação Física, na Educação Infantil.

\section{MÉTODO}

Esta pesquisa define-se como qualitativa e investiga a formação de futuros professores de Educação Física, em relação à formação e interesse em atuar na Educação Infantil.

A pesquisa qualitativa responde a questões muito particulares, pois se ocupa, nas Ciências Sociais, como um nível de realidade que não pode ou não deveria ser quantificada. Ou seja, ela trabalha com o universo dos significados, dos motivos, das aspirações, das crenças, dos valores e das atitudes ${ }^{3}$.

O estudo foi realizado com acadêmicos e professores da Licenciatura em Educação Física, de um curso de graduação do RS. A população foi 49 acadêmicos que possuíam $80 \%$ do curso concluído no semestre de 2014/B. A escolha deste grupo se deu por estes terem concluído as disciplinas didático-pedagógicas, bem como as disciplinas relacionadas à Educação Infantil e por já terem realizado os estágios supervisionados. A amostra foi constituída de 30 acadêmicos.

De acordo com a matriz do curso estudado, os estágios estão dispostos a partir da metade do curso, ou seja, no $5^{\circ}$ semestre se inicia o Estágio Supervisionado I - Anos Iniciais do Ensino Fundamental e os outros dois ocorrem no $6 .^{\circ}$ e $7 .^{\circ}$ semestres. Além dos acadêmicos, três professores do curso que trabalham com disciplinas ligadas a aspectos didático-pedagógicos da Educação Física Escolar, tais como: Psicomotricidade, Educação Física nos Anos Iniciais do Ensino Fundamental e Educação Física para o Ensino Médio foram escolhidas. Vale ressaltar que dois destes professores são supervisores do estágio I e o outro professor é coordenador dos estágios da Licenciatura em Educação Física.

A coleta de dados teve, como instrumento, um questionário, contendo onze questões abertas ou fechadas, uma entrevista semiestruturada composta por oito questões para os professores supervisores e sete questões para o professor coordenador dos estágios. 0 questionário foi entregue aos acadêmicos do curso de Licenciatura em Educação Física durante as aulas da graduação e intervalos destas, no período da noite. Para aqueles que não responderam o questionário pessoalmente, foi enviado um e-mail com o questionário. Com os questionários enviados, solicitamos que o Termo de Consentimento Livre e Esclarecido (TCLE) deveria retornar, assinado juntamente com o questionário. Já, as entrevistas com os professores foram realizadas na universidade, em horário e data previamente definidos por e-mail. Além disso, foram analisados os planos de ensino das disciplinas relacionadas com a Educação Infantil, tais como: Educação Física - Anos Iniciais do Ensino Fundamental, Psicomotricidade, Recreação e Estágio Supervisionado I - Anos Iniciais do Ensino Fundamental.

Vale ressaltar que o projeto deste estudo foi aprovado por um Comitê de Ética e Pesquisa (COEP) e os cuidados éticos devidamente tomados, através do uso do TCLE, que relata as características do estudo e o objetivo do uso das informações coletadas, além de informar que será mantido o sigilo referente às informações relacionadas à privacidade dos participantes. Desta forma, tanto os acadêmicos quanto os professores participantes estiveram cientes de sua participação. 
Para manter o sigilo dos professores na apresentação da análise dos resultados, foram utilizados códigos: entrevista 1 para professor 1, entrevista 2 para professor 2 e entrevista 3 para professor 3 . Os questionários foram enumerados de um a 30, assim, ao se fazer referência, foi utilizado o número do questionário referido.

Após se ter retorno dos questionários foi realizada a análise e interpretação das respostas e, da mesma forma, com as entrevistas realizadas com os professores. Para a análise dos resultados, foram estabelecidas duas categorias: a) Compreensão dos acadêmicos em relação à formação inicial para atuarem com a Educação Infantil e b) A escolha da Educação Infantil como campo de experimentação didático-pedagógica e possível área de atuação profissional. Nas categorias, cruzaram-se as informações das entrevistas, questionários e planos de ensino das disciplinas didático-pedagógicas do curso de Licenciatura em Educação Física, triangulando-se com o referencial teórico.

\section{RESULTADOS E DISCUSSÃO}

Compreensão dos acadêmicos, em relação à formação inicial para atuarem com a Educação Infantil

De acordo com os questionários respondidos, 100\% dos acadêmicos já realizaram o Estágio I - Anos Iniciais do Ensino Fundamental que, de acordo com o Plano de Ensino da disciplina, pode ser realizado na Educação Infantil ou nos Anos Iniciais:

“Desenvolvimento das atividades junto à rede escolar, visando a oferecer a experiência concreta de planejamento do ensino e de docência com crianças na Educação Infantil e nos Anos Iniciais do Ensino Fundamental".

Ao serem questionados sobre o nível de ensino, que realizaram o estágio I, 30\% dos acadêmicos participantes do estudo, optaram por realizá-lo na Educação Infantil, tendo como motivos de escolha, os horários disponíveis e a localização da escola escolhida, conforme respostas abaixo:

"Educação Infantil, pois era mais acessível aos meus horários" (questionário 01).

"Realizei meu estágio com Educação Infantil, pois a escola localizava-se mais perto do meu trabalho" (questionário 03).

Tais justificativas coincidem com o relato de um dos professores supervisores entrevistado:

"Alguns estudantes nossos optam pela Educação Infantil, pela flexibilização de horários, pois é mais fácil pra eles dentro de seu trabalho conseguir sair e adequar seu horário de estágio dentro da educação infantil. Então tem sido uma opção dos estudantes hoje, não todos, mas quase todo semestre, em torno de dois, três alunos vão para a Educação Infantil, justamente pelo horário de trabalho, não por que quer Educação Infantil" (entrevista 1).

Os $70 \%$ dos acadêmicos restantes optaram por estagiar nos Anos Iniciais do Ensino Fundamental, ten- do como justificativa a maturidade das crianças, a preferência de atuação com tal faixa etária e a conciliação de horários da escola com os seus, conforme segue relatos:

"Realizei com uma turma dos Anos Iniciais por gostar mais desta faixa etária" (questionário 11).

"1 ${ }^{\circ}$ ano do Ensino Fundamental, porque foi o que fechou com os meus horários" (questionário 27).

Entendemos o estágio como atividade curricular, pois é uma excelente atividade teórica de conhecimento, de fundamentação, de diálogo e de intervenção na realidade escolar, ou seja, é no ambiente da sala de aula, no contexto da escola que o aluno terá noção da prática docente ${ }^{4}$. Os alunos que disseram já ter atuado com a Educação Infantil, somaram $40 \%$ e pôde-se perceber que aqueles que já possuíam prática com a Educação Infantil optaram por realizar o estágio I, com os Anos Iniciais. Seguem relatos de alunos:

"Foi uma experiência enriquecedora em todos os aspectos. Pessoalmente, acredito ser uma faixa etária com maior proveito pedagógico onde se pode preparar e formar os alunos para práticas saudáveis" (questionário 14).

"Trabalhei cerca de cinco meses, logo que iniciei o curso. Gosto muito de crianças, mas em relação à Educação Física, prefiro faixa etária maior" (questionário 16).

Nas respostas dos acadêmicos, houve relatos de alunos que atuam na Educação Infantil, que realizaram o estágio na mesma escola em que trabalham, mas não aplicam as atividades que cabem a sua profissão, conforme segue relato:

“Trabalho em escola de Educação Infantil, fiz o estágio lá, mas não aplico os meus conhecimentos na turma, pois falta tempo e sou concursada como monitora de Educação Infantil" (questionário 09).

De acordo com tal situação, podemos nos questionar do quão importante é a nossa profissão. Será que ensinamos porque gostamos, porque é importante para o desenvolvimento das crianças, ou ensinamos somente quando somos classificados como professores oumonitores?

Não iremos nos estender em relação à nossa valorização e nem ao trabalho que cada professor realiza, mas eis que surge uma polêmica da qual podemos destacar o preparo dos acadêmicos para atuação na Educação Infantil, pois quando questionados sobre tal tema, $73 \%$ deles afirmaram estar preparados para atuar neste nível de ensino, tendo como suporte a formação profissional e a formação acadêmica que a graduação oferece. Sobre estes aspectos os acadêmicos comentam:

"Me considero preparado, até porque as disciplinas cursadas nos dão um embasamento e muitas vezes uma prática pedagógica em alguns encontros com crianças da Educação Infantil" (questionário 28).

Este relato condiz com o plano de ensino da disciplina de Psicomotricidade, que cita o preparo do professor de Educação Física, para atuar com crianças da Educação Infantil:

"Abordagem da prática psicomotriz educativa: formação teórica/pedagógica do professor de Educa- 
ção Física. Aprendizagem e desenvolvimento infantil, enfoque psicomotor e psicopedagógico da relação professor/criança. Prática educativa e inclusão. Docência, planejamento, metodologia e avaliação para a Educação Infantil (plano de ensino da disciplina de psicomotricidade).

De acordo com as respostas dos questionários, a maioria dos alunos diz possuir preparo para atuar com este nível de ensino, porém quando perguntados sobre seus conhecimentos em relação a métodos de ensino que podem vir a serem aplicados na Educação Infantil, a porcentagem foi apenas de 56\%. Desta forma, podemos questionar o preparo destes alunos para atuar na Educação Infantil e refletir sobre estes futuros professores que julgam estar preparados para atuar com crianças, porém, a maior parte deles não conhece algum método de ensino que possa ser aplicado, em suas aulas na Educação Infantil.

Em sua atuação nessa área o professor deve estar bem subsidiado, devendo ter uma noção clara do seu papel político como formador de cidadãos sujeitos do seu processo de aprendizagem. Para tanto, uma quantidade enorme de conhecimentos se faz necessária, não apenas as técnicas desportivas, mas os processos de desenvolvimento cognitivo, afetivo-social e psicomotor ${ }^{5}$.

Os alunos que dizem não estar preparados para atuar com a Educação Infantil somaram $27 \%$ e justificaram a falta de conhecimentos:

"Não temos conhecimento suficiente para trabaIhar com crianças nessa faixa etária" (questionário 09).

"Acredito não ter conhecimento suficiente, já trabalhei, mas acabávamos sendo 'cuidadoras', e não professoras de Educação Física" (questionário 16).

Partindo do princípio da "falta de conhecimentos", é preciso ressaltar a importância do preparo do professor de Educação Física, pois o Ministério da Educação, as Secretarias Estaduais e as Municipais de Educação deveriam ter mecanismos reguladores e fiscalizadores das escolas privadas infantis, para evitar que elas funcionem sem projeto pedagógico consistente e com professores sem qualificação para atuar nesse nível de ensino que, sem dúvida, requer muito preparo profissional e pessoal ${ }^{6}$.

As contribuições da Educação Física para a Educação Infantil, que os alunos citaram partiram de aprendizagens ligadas ao desenvolvimento motor, com $90 \%$ das citações, e no desenvolvimento cognitivo, com $56 \%$.

Abaixo, o relato dos alunos em relação às contribuições da Educação Física na Educação Infantil:

"As contribuições são no desenvolvimento da parte motora e da parte lúdica e faz com que as crianças consigam resolver sozinhas alguns desafios propostos" (questionário 25).

"A Educação Física na Educação Infantil é essencial para o desenvolvimento cognitivo e sensorial motor da criança" (questionário 01).

As aulas de Educação Física devem ser entendidas como espaços concretos para a construção da compre- ensão da motricidade humana, através da produção de abstrações pela criança, relacionadas à generalização e, esta, aos processos de pensamento ${ }^{7}$

Ainda, em relação ao preparo dos alunos, foi possível identificar através dos questionários quais as disciplinas do currículo que mais contribuem para a formação dos futuros professores. Foram citadas 13 disciplinas, com os seguintes percentuais: Psicomotricidade $83 \%$, Recreação 63\%, Educação Física para os Anos Iniciais 50\%, Desenvolvimento Humano 13\%, Estágio Supervisionado I para os Anos Iniciais, Formação Pessoal, Didática Geral e Pedagogia e Diferenças todas com 10\%, Educação Postural, Cinesiologia, Pedagogia do Movimento Humano, Capoeira e Dança com 3\%.

Em relação às disciplinas citadas pelos alunos, é possível evidenciar a relação que possuem com a Educação Infantil através da disciplina de Psicomotricidade, pois $83 \%$ deles escolheram tal disciplina como a que mais contribui para a Educação Infantil. Em seguida, a disciplina de Recreação aparece com $63 \%$ de escolha, deixando Anos Iniciais do Ensino Fundamental como a terceira mais votada, com $50 \%$, de um total de treze disciplinas destacadas por eles:

"Na psicomotricidade que temos contato com as crianças e o estágio I que pode ser trabalhado com essa faixa etária" (questionário 09).

"As disciplinas de Recreação, Educação Física Anos Iniciais e Psicomotricidade foram as principais disciplinas que contribuíram para a minha formação" (questionário 06).

Vale ressaltar que as três disciplinas mais citadas são ministradas pela mesma professora, que aborda os fatores da Educação Física na Educação Infantil com mais evidência para a compreensão dos alunos. Em relação à Educação Infantil, a professora comenta:

"Na escola, não é juntar um monte de brincadeiras e ir lá brincar com a criançada, é focalizar no desenvolvimento e aprendizagem do que eu quero trabalhar. Dentro da disciplina de recreação eu busco sempre tentar diferenciar isso. Bom, onde acontece a recreação? Quais são os espaços da recreação? Recreação é uma coisa, é fora da escola. Na escola é planejamento, na escola não é recreação, é focalizar a educação física escolar, porque a gente vê muito forte dentro da nossa sociedade esse problema de mistura de temas, de achar que a recreação é educação física" (entrevista 01).

A preferência dos alunos em realizar o Estágio I na Educação Infantil foi menor do que os que optaram pelos Anos Iniciais. Em comparação, percebe-se que a disciplina de Estágio I para os Anos Iniciais do Ensino Fundamental aparece como uma das menos citadas pelos acadêmicos, com $10 \%$ de indicação, o que leva a questionar sobre a percepção dos acadêmicos em relação à contribuição dessa disciplina em seu currículo para a Educação Infantil ou que, pelo menos, não possui tanta evidência com a Educação Infantil.

$\mathrm{Na}$ entrevista com um dos professores supervisores, quando questionado sobre as disciplinas do curso que contribuem para a Educação Infantil, o estágio foi tomado como espaço de formação:

"Acho, também muito válido os nossos encontros 
gerais do estágio, ali a gente começa a tirar duvidas com os alunos, ali dá pra enriquecer e os encontros individuais conseguimos abordar especificamente o que vai acontecer no dia a dia da escola, então, acho que isso aí hoje é o que estrutura mais as aulas dos nossos alunos na aplicação do estágio" (entrevista 02).

O relato do professor nos mostra que o Estágio I tem fatores enriquecedores para a Educação Infantil mas, muitas vezes, tal disciplina passa despercebida, pelos alunos, como possível contribuição para a Educação Infantil.

A escolha da Educação Infantil como campo de experimentação didático-pedagógica e possível área de atuação profissional

Quando perguntados sobre o possível campo de atuação no futuro, $67 \%$ dos alunos mencionaram ter alguma opção de escolha. Na parte escolar, o nível de ensino mais citado foi os Anos Iniciais do Ensino Fundamental, com 30\% de escolha. Os Anos Finais do Ensino Fundamental e/ou Ensino Médio somaram 20\% de escolha, seguido de Educação Infantil e/ou Anos Iniciais do Ensino Fundamental com 15\%. O Ensino Médio também teve 15\%, deixando a Educação Infantil, os Anos Finais do Ensino Fundamental e o Ensino Médio, ambas com $05 \%$ de escolha cada. Fora da escola, a área citada foi a $3^{\mathrm{a}}$ idade, com $5 \%$ de escolha. Pode-se verificar que a maioria dos alunos possui afinidade e interesse por alguma área de atuação, e que 33\% deles não têm um nível de ensino, com o qual mais se identificam, conforme segue relato:

"Não tenho preferência, gosto de todos os níveis de ensino" (questionário 06).

"Estou preparado para qualquer nível de ensino" (questionário 15).

Para atuar com a Educação Física na Educação Infantil, assim como em outros níveis de ensino, é preciso que os futuros professores tenham conhecimentos relacionados a esta área, pois a Educação Física escolar tem as mesmas metas que qualquer outra disciplina do currículo, ou seja, possibilitar o desenvolvimento do potencial humano. Sua especificidade é a busca das possibilidades lúdicas, expressivas e comunicativas da cultura corporal, trazendo como conseqüência a aceitação de si mesmo e do próprio corpo e melhor relação com os demais ${ }^{8}$

Sendo assim, questionamos os alunos para verificar se os aprendizados ao longo do curso de Licenciatura em Educação Física contemplam a temática da Educação Física na Educação Infantil e obtivemos um total de $43 \%$ de alunos que acreditam que as aprendizagens oferecidas na instituição contemplam sim o seu currículo, para atuação na Educação Infantil, conforme relato:

"Sim, as temáticas citadas foram ministradas por profissionais qualificados que dominam o assunto" (questionário 15).

Os alunos que alegaram não ter no curso aprendizagens que contemplam a Educação Física na Educação Infantil somaram um total de $57 \%$, e tiveram como justificativa a falta de eventos e o despreparo para atuar com este nível de ensino:

"Creio que o ensino é muito fraco quando focado na Educação Infantil. O curso tem muito a melhorar" (questionário 07).

"No meu ponto de vista a Educação Física para a Educação Infantil é muito pouco contemplada no curso" (questionário 20).

Como sugestões de melhoria do currículo, $83 \%$ dos alunos disseram que deve haver uma melhoria em alguns pontos do curso. A opção de incluir mais eventos/seminários/palestras obteve $20 \%$ de indicação por parte dos acadêmicos. Já, a inclusão de novas disciplinas voltadas para a Educação infantil, obteve $52 \%$ de indicação. Os alunos que acreditam na inserção, tanto de eventos/seminários e palestras, bem como de disciplinas, somaram $28 \%$.

"Enquanto formanda, acredito precisar de mais disciplinas, palestras e eventos que tratem sobre essa temática, ainda não há uma clareza sobre o que deve ser desenvolvido na área da Educação Física com crianças tão pequenas" (questionário 05).

Um dos docentes entrevistados ressalta a importância de readequar as disciplinas que já existem, sem precisar incluir mais disciplinas, conforme relato:

"Acho que a mudança que fizemos no currículo do curso, retirando a disciplina de Psicomotricidade e inserindo Educação Física e Infância, dará uma outra cara à disciplina, além de trazer outras discussões" (entrevista 03).

Em contrapartida, outro docente também defende a necessidade de rever, no currículo, as disciplinas que tratam da Educação Infantil:

“Sim, até isso vai virar realidade, já foi discutido entre o colegiado e no próximo currículo que vai abrir da educação física vai ter. A gente precisa dar uma atenção especial, e isso é um somatório de várias questões [...] os nossos professores que nós estamos formando precisam estar preparados para essa atuação, não só como uma experimentação de ver como é, mas principalmente pra eles fazerem uma atuação qualificada dentro da educação infantil e realmente ter a capacidade de demonstrar que ter um professor é bem diferente e traz muito mais benefícios do que simplesmente as atividades realizadas com o pessoal de outras áreas que não tem o mesmo estudo e a mesma preparação que a gente" (entrevista 01).

Já, o professor entrevistado 02 somente comenta sobre uma nova disciplina voltada especificamente para a Educação Infantil, pelo fato de poder juntar todos os elementos específicos para essa área:

“Eu acredito que vai auxiliar nessa questão do planejar, do pensar e do preparar o aluno para atuar na Educação Infantil, talvez por ter um nome na disciplina, talvez os alunos vão relacionar mais a esse nível de ensino" (entrevista 02)

Nos relatos dos docentes, percebe-se uma divergência de opiniões, pois os entrevistados 02 e 03 não 
afirmam a importância da inserção de mais disciplinas, mas sim da importância da readequação das disciplinas que já existem diferenciando as opiniões, pois o entrevistado 01 afirma ser necessária a inclusão de uma disciplina que aborde a qualificação de atuação dos discentes para atuar na Educação Infantil.

Seguindo a ideia de incluir algo ou não no currículo, todos os três professores relataram a importância de haver mais eventos (palestras, seminários e cursos) voltados para a Educação Infantil. O entrevistado 01 comenta que os eventos diminuíram muito em relação ao início do curso de Educação Física na universidade, quando o professor coordenador do curso possuía formação específica para os anos iniciais do ensino fundamental, o que acabava influenciando nos eventos que eram realizados na instituição. Da mesma forma, o professor faz uma comparação com as áreas de interesse daquele tempo, com as áreas de interesse atuais:

"Ele montou um currículo que foi começando a educação física e, a medida que o curso foi crescendo rapidamente, muitos outros interesses acabaram sendo incorporados, tanto é que o curso chegou a dobrar, sendo um licenciatura e outro bacharelado, porque a medida que foi incorporando vários interesses dentro do curso de educação física, foi se perdendo um tanto dos interesses na Educação Infantil e também na Educação Física escolar" (entrevista 01).

$\mathrm{O}$ entrevistado número 02 comenta sobre voltar a ter eventos como se tinha há anos atrás na universidade, quando autores realizavam palestras voltadas à Educação Infantil:

"Talvez agora estaria na hora de retomar e se repensar novamente mais palestras e cursos para a educação infantil, pois era muito forte e de repente parou-se, não se fez mais nenhuma ação, nenhuma palestra especificamente voltada pra essa questão" (entrevista 02).

Tal relato possui a mesma característica do professor 01 que descreve como a Educação Infantil era abordada nos eventos do curso, logo em seu início. Já, o último professor entrevistado justifica que pouco tem sido feito em relação aos eventos voltados para a Educação Física nessa etapa:

"No curso de Educação Física eu diria que temos feito poucas coisas. Penso também que tem sido bastante delicada a questão de se oferecer eventos, cursos focados para o trabalho com crianças na escola" (entrevista 03).

Com tais dizeres, pode-se perceber que há coerência entre os três docentes e os 30 discentes em relação à falta de eventos que ofereçam capacitação para os futuros professores que irão atuar com a Educação Infantil. Acredita-se que o currículo possa ser reformulado em relação às atividades extracurriculares do curso, pois com os relatos obtidos, pode-se concluir que a carência realmente existe, o que consecutivamente acaba acarretando no despreparo dos acadêmicos para atuação neste nível de ensino.

O professor deve levar a sério a sua formação, deve estudar durante e após sua formação, deve estar à altura das suas obrigações, deve ensinar e aprender com os alunos ${ }^{9}$.

Comentários que auxiliassem a pesquisa foram solicitados aos alunos no final do questionário. Em um relato que busca o melhor preparo aos acadêmicos, um aluno cita a sugestão de criar grupos de trabalho, conforme segue:

"Grupos de trabalho para pesquisa e troca de experiência. Por exemplo, um programa como o PIBID, introduzir no currículo para vivenciar mais atividades práticas" (questionário 14).

O Programa Institucional de Bolsa de Iniciação à Docência (PIBID) busca aprimorar o processo de formação de futuros docentes, para a educação básica além de contribuir para o exercício da teoria e prática que são necessárias para a formação dos docentes ${ }^{10}$. Entendemos que programas assim ampliam a experiência dos alunos para atuar em sala de aula, pois estes grupos de trabalho oportunizam vivências diretamente relacionadas à escola.

Aos professores entrevistados também foram solicitados comentários que auxiliassem a pesquisa:

"Precisamos trabalhar de uma forma mais confortável, com atividades de aventura, que possamos aceitar melhor as árvores, o "trepa-trepa", o barranco, a terra, que eu acho que são elementos que ajudam muito nesse processo da criança descobrindo o próprio corpo, criando o próprio corpo" (entrevista 03).

A entrevista número 01 não teve comentários, porém nos comentários das entrevistas 02 e 03, ambos os professores acabam trazendo novamente a questão do preparo dos acadêmicos para atuar com a Educação Infantil:

"A compreensão da Educação Física na Educação Infantil vai partir do momento em que os alunos tiverem mais experimentação, uma vivencia maior, dentro da Educação Infantil" (entrevista 02).

"Acho que às vezes a lógica é muito funcional, é muito para desenvolver habilidades motoras, dos tradicionais jogos de correr, pega-pega, esconde-esconde, jogo de estafetas, sendo muito pouco inserida a dança, a capoeira e a ginástica que também fazem parte desse universo da educação Infantil" (entrevista 03).

Desta forma, cria-se uma afinidade entre os comentários de professores e alunos, o que mostra que a necessidade de preparar melhor os acadêmicos para atuar na Educação Infantil realmente existe.

\section{CONSIDERACִÕES FINAIS}

Pôde-se perceber que esta pesquisa abordou questões muito particulares dos alunos que responderam os questionários e dos professores entrevistados. De acordo com os questionários respondidos, conclui-se que todos os alunos participantes deste estudo já realizaram a disciplina de Estágio Supervisionado I, no qual verificamos que a preferência da realização foi nos Anos Iniciais do Ensino Fundamental, e não na Educação Infantil. De acordo com os relatos, tanto dos professores entrevistados, quanto dos alunos questionados, as justificativas foram as mesmas: localização da escola 
e a flexibilização dos horários pessoais.

Em relação à experiência com a Educação Infantil, percebemos uma diferença entre a atuação neste nível de ensino e a escolha de atuação no estágio obrigatório. Os alunos que já haviam trabalhado com este nível de ensino, não optaram por realizar o Estágio com a Educação Infantil, e sim com os Anos Iniciais. Tal característica pode ser muito importante, pois isto nos traz uma reflexão sobre as aulas de estágio, sendo possível recordar que os professores procuravam ressaltar a questão da realização do estágio em níveis de ensino que os alunos ainda não possuíam vivências, sendo o objetivo da disciplina, a experimentação de atuar com determinada turma/faixa etária com que o futuro professor ainda não atuou.

Referente à atuação nesta etapa, o número de alunos que se considera preparado para atuar neste nível de ensino é maior do que o número de alunos que diz não ter conhecimento sobre os métodos de ensino, que podem ser aplicados na Educação Infantil. Isto nos faz refletir sobre como está se dando a formação dos acadêmicos, pois se a maioria afirma estar preparado para atuar neste nível, este mesmo número de alunos deveria ter conhecimento sobre os métodos de ensino. Os alunos que afirmaram não ter preparo, justificam-se por não ter conhecimentos suficientes para trabalhar com crianças pequenas.

Em relação às contribuições da Educação Física para a Educação Infantil, o mais lembrado pelos alunos foi o Desenvolvimento Motor, seguido do Desenvolvimento Cognitivo. Isto nos mostra que os alunos estão cientes em relação à parte pedagógica que pode ser trabalhada na Educação Infantil, porém, acaba mantendo os alunos presos muitas vezes a práticas repetitivas.

A Educação Física tem valor imenso, pois oferece à criança a oportunidade de vivenciar diversas formas de organização, de realização de tarefas ou atividades em que possibilita a sua transformação, no meio em que está inserida ${ }^{11}$.

Estando cientes de tais contribuições, os alunos citaram 13 disciplinas que, para eles, trazem contribuições para a sua formação e atuação na Educação Infantil, ressaltando assim que $30 \%$ do total de disciplinas do curso de Licenciatura em Educação Física, possuem relação com a etapa.

Dentre as disciplinas citadas, o Estágio obrigatório I foi o menos lembrado pelos alunos, o que nos traz uma preocupação, pois de acordo com o relato do professor entrevistado 02, tal disciplina é muito enriquecedora, já que aborda a realidade da escola e a vivência diária de um professor. Segundo o Plano de Ensino da disciplina, no Estágio o aluno exercita a autonomia e a sua independência no planejamento e na execução de tarefas docentes, ou seja, é nele que o acadêmico poderá ter total noção do que é atuar com o nível de ensino escolhido.

Em relação ao curso, percebemos que a maior parte dos acadêmicos defende a ideia de incluir algo no currículo, que possa contemplar a Educação Física diretamente na Educação Infantil, tendo como principal escolha, a inclusão de disciplinas que tragam contribui- ções para melhor atuação deles neste nível de ensino. Já, os docentes entrevistados acreditam que a realização de eventos voltados para esta etapa são necessários para que se possa preparar melhor os alunos que futuramente irão atuar com este nível de ensino.

$\mathrm{O}$ fato que mais chamou a atenção neste estudo foi o interesse de atuação dos alunos. Podemos perceber que a Educação Infantil não vem como o "carro chefe" na hora de escolher o nível de ensino para atuar, pois apenas $5 \%$ dos alunos questionados mostraram interesse em atuar somente nesse nível de ensino.

Ao final do questionário e da entrevista, solicitamos comentários que pudessem auxiliar a nossa pesquisa, e percebemos que existe uma preocupação, tanto por parte dos professores, como por parte dos alunos, em se ter uma melhor compreensão do que é a Educação Física na Educação Infantil. Verificamos que esta preocupação apareceu não somente nesta questão, mas em várias partes deste estudo tal carência surgiu, pois alunos e professores citaram medidas que podem ser tomadas para que as aprendizagens contemplem a área. Acreditamos que os alunos, ao concluírem o curso de Licenciatura em Educação Física, devem obter uma gama de conhecimentos ligados à experiência acadêmica para que sejam capazes de aplicar toda sua vivência e conhecimentos obtidos na graduação, em aulas de Educação Física qualificadas para a Educação Básica.

\section{REFERÊNCIAS}

1. Horn MGS. Sabores, cores, sons, aromas. A organização dos espaços na educação infantil. Porto Alegre, RS. Editora Artmed, 2004.

2. Brasil, L. D. B. E. N. Estabelece as leis de diretrizes e bases da educação nacional: 1996. Lei nº 9394. Disponível em: <http://www.planalto.gov.br/ccivil_03/leis/l9394.htm>. Acesso em: abril de 2014.

3. Mynaio MCS. Pesquisa Social: Teoria, método e criatividade. Petrópolis, RJ. Editora Vozes, 2008.

4. Pimenta SG, Lima MS. Estágio e docência: diferentes concepções. Rev Poíesis Pedagógica. 2005/2006; 3(3,4): 5-24.

5. Mattos MG, Neira MG. Educação física infantil: construindo o movimento na escola. Guarulhos, SP. Editora Phorte, 1999.

6. Negrine AS, Negrine CS. Educação Infantil: pensando, refletindo, propondo. Caxias do Sul, RS. Editora Educs, 2010.

7. Oliveira AAB, Palma APTV, Palma JAV. Educação Física e a Organização Curricular: educação infantil, ensino fundamental, ensino médio. Londrina, PR. Editora Eduel, 2010.

8. Aravena CJO, Gallardo JSP, Oliveira AAB. Didática de educação física: a criança em movimento: jogo, prazer e transformação. São Paulo, SP. Editora FTD, 1998.

9. Caparroz FE, Bracht V. O tempo e o lugar de uma didática da educação física. Rev Bras Cie Esp. 2007; 28(2): 21-37.

10. Centro Universitário Univates [online]. Rio Grande do Sul, Brasil, 2014. Disponível em: <http://www.univates.br/ pibid/?page _id=4>. Acesso em novembro de 2014.

11. Neuenfeldt $\bar{D} J$, Rosa DC. Análise da formação inicial e dos campos de atuação dos egressos de um curso de Educação Física - Licenciatura, RS, Brasil. Rev EFDeportes. 2013; 18(182). 